\title{
Analisis Perbandingan Tingkat Pengetahuan Peringatan Dini di Sekolah Muhammadiyah di Kabupaten Karanganyar
}

\author{
Maharani Retno Wulandari, Araa Reda Astara, Nur Zahro Madya A, \\ Mohammad Anggit S, Muhammad Taufiq Ismail A, Farizki Yunarta \\ Universitas Muhammadiyah Surakarta \\ Jl. A. Yani, Mendungan, Pabelan, Kartasura, Kabupaten Sukoharjo, Jawa Tengah 57162 \\ Email: a610160019@student.ums.ac.id
}

\begin{abstract}
Landslide disasters currently happens a lot in Indonesia. One of them, namely the region of karanganyar Regency. The high rainfall intensity and geographical location greatly affects the occurrence of landslide. Landslides caused an awful lot of loss both economically, socially and casualties. Therefore, need for early warning systems to mitigate the effects caused. Knowledge of early warning can prepare individuals to be more prepared in the face of disaster. Implementation of effective to transfer the knowledge of landslide early warning through the school. That is because the school has a younger generation of potential as agents of change. Therefore, the purpose of this research is to know the level of knowledge of early warning in 33 schools in Karanganyar Regency, so by understanding the level of knowledge of early warning can be used as guidelines for further policy. This research uses descriptive quantitative methods with data analysis using microsoft excel. Of the 33 schools, which provided the sample noted that 27 have low knowledge levels and 6 among them has a moderate level of knowledge. Many factors affect the low level of knowledge of early warning is a lack of disaster material and dissemination of disaster affects the level of knowledge.
\end{abstract}

Keywords: early warning, disaster, landslide, school, preparedness

\begin{abstract}
Abstrak
Bencana tanah longsor saat ini marak terjadi di Indonesia. Salah satunya yaitu wilayah kabupaten karanganyar. Intensitas curah hujan yang tinggi dan letak geografis sangat mempengaruhi terjadinya bencana longsor. Tanah longsor tidak hanya mengakibatkan kerugian secara finansial, akan tetapi banyak sekali kerugian yang ditimbulkan seperti korban jiwa, dan sosial. Maka dari itu perlu adanya sistem peringatan dini untuk mengurangi dampak yang ditimbulkan. Pengetahuan akan peringatan dini dapat mempersiapkan individu agar lebih siap dalam menghadapi bencana. Pengimplementasian yang efektif untuk menyalurkan pengetahuan akan peringatan dini bencana longsor yaitu melalui sekolah. Hal tersebut dikarenakan sekolah memiliki generasi muda yang berpotensi sebagai agent of change. Maka dari itu tujuan penelitian ini untuk mengetahui tingkat pengetahuan peringatan dini di 33 sekolah di Kabupaten Karanganyar, sehingga dengan mengerti tingkat pengetahuan akan peringatan dini dapat dijadikan pedoman untuk kebijakan selanjutnya. Penelitian ini menggunakan metode kuantitatif deskriptif dengan analisis data menggunakan microsoft excel. Dari ke 33 sekolah yang dijadikan sample diketahui bahwa 27 diantaranya memiliki tingkat pengetahuan yang rendah dan 6 diantaranya memiliki tingkat pengetahuan sedang. Banyak faktor yang mempengaruhi rendahnya tingkat pengetahuan peringatan dini salah satunya kondisi siswa yang cenderung belum matang dan kurangnya materi kebencanaan dan sosialisasi tentang kebencanaan mempengaruhi tingkat pengetahuan.
\end{abstract}

Kata Kunci: Peringatan dini, bencana, tanah longsor, sekolah, kesiapsiagaan 


\section{PENDAHULUAN}

Ancaman bencana di Indonesia dapat terjadi kapan saja karena letak Indonesia yang berada diantara pertemuan 3 lempeng aktif dimana membentuk suatu jajaran pegunungan api aktif. Gerakan konvergen suatu lempeng yang bersubduksi akan membentuk morfologi Indonesia. Gerakan Konvergen membentuk Indonesia menjadi negara yang indah akan alamnya selain keindahan alamnya juga tersimpan berjuta potensi bencana yang sewaktu-waktu dapat terjadi. Relief permukaan bumi yang khas dan sangat bervariasi seperti pegunungan dengan lereng yang curam menyimpan potensi longsor yang tinggi dan wilayah datar seperti pantai menyimpan potensi Tsunami. Hal tersebutlah yang menjadi keindahan Indonesia tidak lepas akan potensi bencana. Rangkaian bencana tersebut seharusnya membentuk masyarakat sadar dan siapsiaga akan bencana sehingga masyarakat diharapkan reaktif terhadap bencana dengan pemahaman penanggulangan bencana yang tinggi.

Undang-undang Nomor 24 tahun 2007, tentang penanggulangan bencana merupakan landasan hukum penyelenggaraan penanggulangan bencana di Indonesia. Dalam tahap penanggulangan bencana, kegiatan yang dilakukan mulai dari pencegahan, mitigasi, tanggap darurat, serta rehabilitasi dan rekonstruksi. Kegiatan tersebut diharapkan mampu menekan kerugian yang ditimbulkan. Apalagi akhirakhir ini Indonesia sering sekali mengalami bencana (Negara Kesatuan Republik Indonesia, 2007).

Pada tahun 2011 hingga 2015, tercatat terjadi 2.425 kejadian bencana gerakan tanah. Kejadian tersebut tersebar diseluruh wilayah Indonesia. Kejadian gerakan tanah terbanyak dijumpai di Provinsi Jawa Tengah, Jawa Barat, Jawa Timur, Sumatera Barat dan Kalimantan Timur. Bencana gerakan tanah tersebut telah mengakibatkan 1.163 jiwa meninggal, 112 orang hilang, 973 orang terluka dan sekitar 48.191 orang mengungsi (BNPB, 2016).

Bencana tanah longsor merupakan jenis bencana geologi yang sering terjadi di Indonesia. Menurut Sutikno (1994) dalam (Setiawan, 2014) tanah longsor atau sering disebut dengan gerakan massa tanah adalah proses perpindahan atau pergerakan massa tanah dengan arah miring atau vertikal dari kedudukan semula sebagai akibat gaya berat. Kejaian longsor dapat dipicu adanaya curah hujan yang tinggi, lereng yang curam, tingginya proses pelapukan, variasi batuan dan struktur geologi, serta perubahan penggunaan lahan yang tinggi. Karanganyar adalah salah satu kabupaten di Provinsi Jawa Tengah yang sering mengalami bencana longsor. Data yang diterbitkan oleh BPBD Kabupaten Karanganyar (2012) menyatakan bahwa, selama tahun 2011 tercatat kejadian bencana longsor 34 kejadian, angin puting beliung 15 kejadian, banjir 3 kejadian dan kebakaran 29 kali (N. Setiawan, 2007). Data tersebut menunjukkan bahwa bencana utama yang paling sering terjadi di Kabupaten Karanganyar adalah tanah longsor.

Kabupaten Karanganyar terletak pada ketinggian rata-rata 511 meter diatas permukaan laut serta beriklim tropis dengan temperatur 22-31 derajat celcius. Adapun wilayah terendah di Kabupaten Karanganyar mencapai 2000 meter diatas permukaan laut (Badan Pusat Statistik (BPS), 2018). Kondisi tersebut membuat sebagian wilayah Karanganyar rentan akan bencana longsor hal tersebut di dukung dengan data dari BPBD Kabupaten Karanganyar (2012) berupa peta kerawanan bencana longsor.

Untuk mengurangi dampak yang ditimbulkan maka perlu adanya sistem peringatan dini. Sistem peringatan di Indonesia sendiri masih belum baik dikarenakan banyak dijumpai peristiwa dimana belum adanya kesiapan baik dari masyarakat maupun pemerintah. Pemerintah sendiri terkadang baru turun tangan setelah bencana itu terjadi. Terkadang pemerintah hanya memberikan alat penanda bencana yang tentu saja sangat bermanfaat bagi masyarakat akan tetapi masyarakat terkadang kurang bisa menjaga alat tersebut, dan sering sekali pada saat terjadinya bencana ditemukan alat yang malah rusak. Maka dari itu disamping menjaga alat yang ada diharapkan masyarakat lebih menyadari tentang kesiapsiagaan bencana.

Kesiapsiagaan menghadapi bencana perlu diimplementasikan sejak dini salah satu pengimplementasian yaitu disekolah, karena selain mempersiapkan kesiapsiagaan sejak dini kepada peserta didik yang merupakan 
generasi emas penerus bangsa, sekolah merupakan faktor sentral anak-anak dalam pengembangan diri sehingga apabila suatu saat terjadi bencana dan sekolah mengalami kerusakan, hal tersebut membuat aktivitas kegiatan belajar mengajar menjadi terhenti. Maka kesiapsiagaan bencana disekolah sangat penting terutama untuk daerah yang rawan dan sering terjadinya bencana. Sekolah yang berada di kawasan bencana longsor diharapkan membangun sistem peringatan dini yang baik dari beberapa komponen yang ada pada sekolah seperti kepala sekolah, guru maupun karyawan dan peserta didik.

\section{METODOLOGI PENELITIAN}

Penelitian ini merupakan jenis penelitian deskriptif dengan pendekatan kuantitatif. Data kuantitatif dikumpulkan dengan menggunakan instrumen penelitian berupa angket yang berisikan daftar pertanyaan (kuesioner). Dalam pendekatan kuantitatif peneliti melakukan suatu rangkaian penelitian yang berawal dari sejumlah teori, dan kemudian dideduksikan menjadi suatu hipotesis dan asumsi-asumsi suatu kerangka pemikiran yang terjabarkan dalam sebuah model analisis, yang terdiri dari variabelvariabel yang mengarah kepada operasionalisasi konsep. Penelitian kuantitatif sangat terkait dengan teknik-teknik survei seperti penyebaran kuesioner, eksperimen, observasi terstruktur, analisis statistik dan sebagainya (Brannen, 1997).

Variabel tersebut dapat direpresentasikan secara numerik sebagai frekuensi atau tingkat. Hubungan antar variabel tersebut juga dapat dieksplorasi dengan teknik statistik, dan diakses melalui penelitian yang memperkenalkan rangsangan dan pengukuran sistematis. Metode ini mendasarkan penelitian pada penyelidikan jumlah atau frekuensi suatu kejadian atau fenomena. Metode kuantitatif diterapkan dalam empat metode yaitu survei, eksperimen, analisis isi kuantitatif, dan analisis data sekunder (Sudaryono, 2018).

Penelitian ini dilaksanakan di Kabupaten Karanganyar khususnya SD, SMP, dan SMA Muhammadiyah di Karanganyar. Penelitian dilakukan selama 3 bulan yaitu dari bulan Oktober hingga Desember 2018. Survei lokasi dilakukan untuk melihat medan dan topografi sekolah-sekolah Muhammadiyah di Kabupaten Karanganyar. Dan menentukan titik koordinat pada masingmasing sekolah yang telah ditetapkan. Diadakannya survei dengan tujuan untuk meninjau kondisi lingkungan sekitar sekolah dan mengukur tingkat mobilitas dan aksesibilitas menuju sekolah masing-masing tersebut. Penelitian ini dilaksanakan pada sekolah-sekolah Muhammadiyah di Kabupaten Karanganyar yang memiliki risiko atau rawan akan bencana, terdapat 33 sekolah yang rawan akan bencana, seperti yang disajikan pada tabel 1 .

Tabel 1. Daftar Sekolah di Muhammadiyah di Kabupaten Surakarta

\begin{tabular}{clcl}
\hline No & Nama SekOlah & No & Nama Sekolah \\
\hline 1 & MIM KALIWULUH & 18 & SMP MUH 1O KARANGANYAR \\
2 & MIM NGENTAK & 19 & SMP DARUL ARQAM \\
3 & MIM NGWARU & 20 & SMP 3 MUH KARANGPANDAN \\
4 & MIM MUNGGUR & 21 & SD MUH PROGRAM UNGGULAN BOTOK \\
5 & SMA MUH 5 KARANGANYAR & 22 & MTS MUH 6 KARANGANYAR \\
6 & SD MUH PLOSOREJO & 23 & SD MUH DARUL FALAH \\
7 & MIM BLORAN & 24 & MIM NANGSRI \\
8 & SMP MUH 4 MOJOGEDANG & 25 & SD IT JUMAPOLO \\
9 & MIM DUNGBANG & 26 & MIM CEPORAN \\
10 & MIM PARAKAN & 27 & SMK MUH 5 KARANGANYAR \\
11 & MTS MUH JUMANTONO & 28 & MIM KARAN \\
12 & MTS MUH 4 MOJOGEDANG & 29 & SMP MUH 8 KEBAKRAMAT \\
13 & MIM MERGOMULYA & 30 & SMA MUH 1 KARANGANYAR \\
14 & MTS MUH 2 KARANGANYAR & 31 & MIM UNGGULAN KARANGANYAR \\
15 & SMP MUH 9 JATEN & 32 & MIM BULAK \\
16 & KARANGANYAR & 33 & MIM CEKEL \\
17 & SD MUH 6 JENAWI & & \\
\hline
\end{tabular}


Dengan mengambil responden dari Guru, Siswa, Kepala Sekolah, dan Masyarakat sekitar dengan menggunakan teknik pengambilan sample statified (Stratified Random Sampling).

Populasi adalah kumpulan dari satuansatuan elementer yang mempunyai karakteristik dasar atau dianggap sama. Karakteristik dasar dicerminkan dalam bentuk ukuran-ukuran tertentu (Yunus, 2010). Populasi dicerminkan dalam bentuk ukuran-ukuran tertentu yang digunakan pada penelitian ini adalah bangunan di 33 sekolah Yayasan Muhammadiyah se-Kabupaten Karanganyar.

Menurut Yunus (2010) sampel merupakan kata benda yang mengandung pengertian objek-objek atau bagian dari populasi yang akan diteliti dan dimanfaatkan untuk memperoleh gambaran mengenai karakteristik populasi. Sampel dalam penelitian yang digunakan pada penelitian ini adalah sekolah yang tergolong dalam rawan bencana tanah longsor, yaitu SD IT Muhammadiyah Jumapolo, SD

Data yang dikumpulkan dan diperoleh dalam penelitian berupa datadata primer dan sekunder.

1. Data primer adalah data yang diambil secara langsung dari sumbernya. Data primer yang digunakan dalam penelitian ini adalah observasi lapangan.

2. Data sekunder adalah data-data, dokumen, referensi yang mendukung seperti buku, kumpulan artikel, kumpulan jurnal publikasi maupun informasi sumber-sumber pendukung lain.

Teknik pengumpulan data yang dilakukan oleh penulis yaitu, observasi dan dokumentasi.

1. Observasi

Observasi sebagai suatu aktivitas yang memperhatikan sesuatu dengan menggunakan mata atau observasi merupakan pengamatan yang meliputi kegiatan pemuatan perhatian terhadap suatu obyek dengan menggunakan seluruh alat indra, sehingga mengobservasi dapat dilakukan melalui penglihatan, penciuman, pendengaran, perabaan,
Muhammadiyah Jatiyoso, MI Muhammadiyah Darul Falah Jenawi, dan SMP Muhammadiyah 6 Jenawi.

Metode sampling adalah cara atau teknik yang digunakan dalam pengambilan sampel penelitian. Pada penelitian ini menggunakan jenis Purposive Sampling yaitu teknik penentuan sampel didasarkan atas ciri-ciri populasi yang sudah diketahui sebelumnya dan berdasarkan tujuan penelitian atau permasalahan peneliti.

Penelitian dilaksanakan selama tiga hari pada tanggal 11-13 Oktober 2018 di Sekolah Yayasan Muhammadiyah yang tergolong rawan bencana tanah longsor di Kabupaten Karanganyar. Pengumpulan data kuantitatif didapatkan dengan menggunakan kuesioner, panduan wawancara, dan observasi. Kuisioner yang digunakan dari LIPI yang dibatasi dengan 4 parameter yakni Pengetahuan Tentang Bencana (KAP), Rencana Kesiapsiagaan Keluarga dari Bencana (EP), Peringatan Bencana (WS), Mobilisasi Sumber Daya (RMC).

dan pengecap. Apa yang dikatakan ini sebenarnya adalah pengamatan langsung, didalami artian penelitian observasi dapat dilakukan dengan tes, kuesioner, rekaman gambar, rekaman suara (Surakhmad, 1990).

2. Dokumentasi

Dokumentasi yaitu mencari data, mengenai hal-hal atau variabel yang berupa catatan, transkip, buku, surat kabar, majalah, prasasti, notulen rapat, legger, agenda, dan sebagainya (Surakhmad, 1990).

Teknik analisis data merupakan suatu langkah yang paling menentukan dari suatu penelitian, karena analisis data berfungsi untuk menyimpulkan dan mengetahui hasil dari penelitian. Analisis dilakukan dengan pengolahan data menggunakan software Microsoft Exel, kemudian hasil dari pengolahan dapat di klasifikasikan sesuai parameter yang ada.

\footnotetext{
HASIL PENELITIAN DAN PEMBAHASAN Tingkat Pengetahuan Kepala Sekolah mengenai peringatan dini
} 
Rata-rata tingkat pengetahuan Kepala Sekolah mengenai peringatan dini bencana tanah longsor yang ada di Kabupaten Karanganyar berada pada tingkat rendah. Karena hanya terdapat 4 sekolahan yang tingkat pengetahuannya tentang peringatan dini tanah longsor pada tingkat sedang dan hanya terdapat 1 sekolah yang memiliki tingkat tinggi yaitu MI Muhammadiyah Cekel. Grafik tingkat pengetahuan kepala sekolah mengenai peringatan dini dapat dilihat pada Gambar 1.

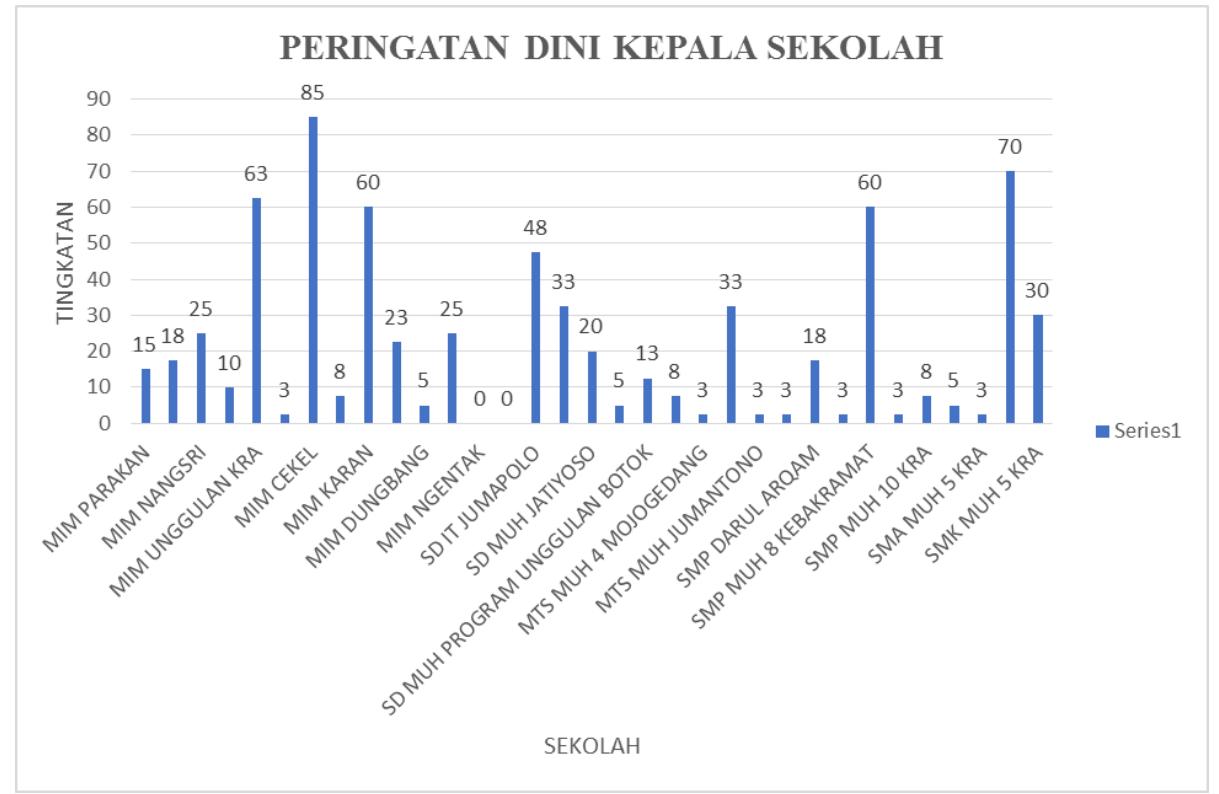

Gambar 1. Tingkat Pengetahuan Kepala Sekolah terhadap Peringatan Dini

\section{Tingkat Pengetahuan Guru di sekolah mengenai peringatan dini}

Berdasarkan hasil analisis, rata-rata tingkat pengetahuan guru mengenai sistem peringatan dini tanah longsor yang ada di Kabupaten Karanganyar berada pada

tingkat sedang. Karena total ada 11 sekolahan yang tingkat pengetahuannya tentang peringatan dini tanah longsor masih dalam tingkatan rendah.

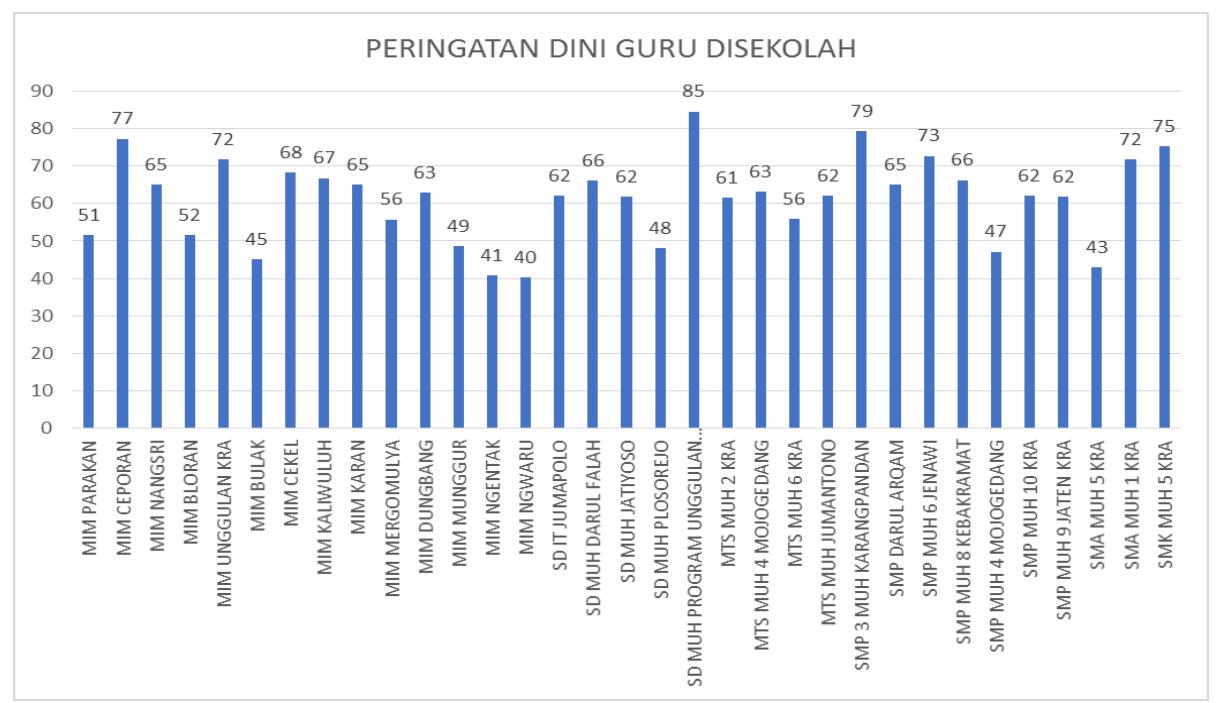

Gambar 2. Tingkat Pengetahuan Guru terhadap Peringatan Dini 
Tingkat Pengetahuan Murid Sekolah Dasar (SD) di sekolah mengenai peringatan dini

Berdasarkan hasil analisis data yang disajikan pada Gambar 3, dapat dilihat bahwa pengetahuan murid sekolah dasar terhadap peringatan dini mengenai bencana tanah longsor di Kabupaten Karanganyar menunjukkan kategori rendah.

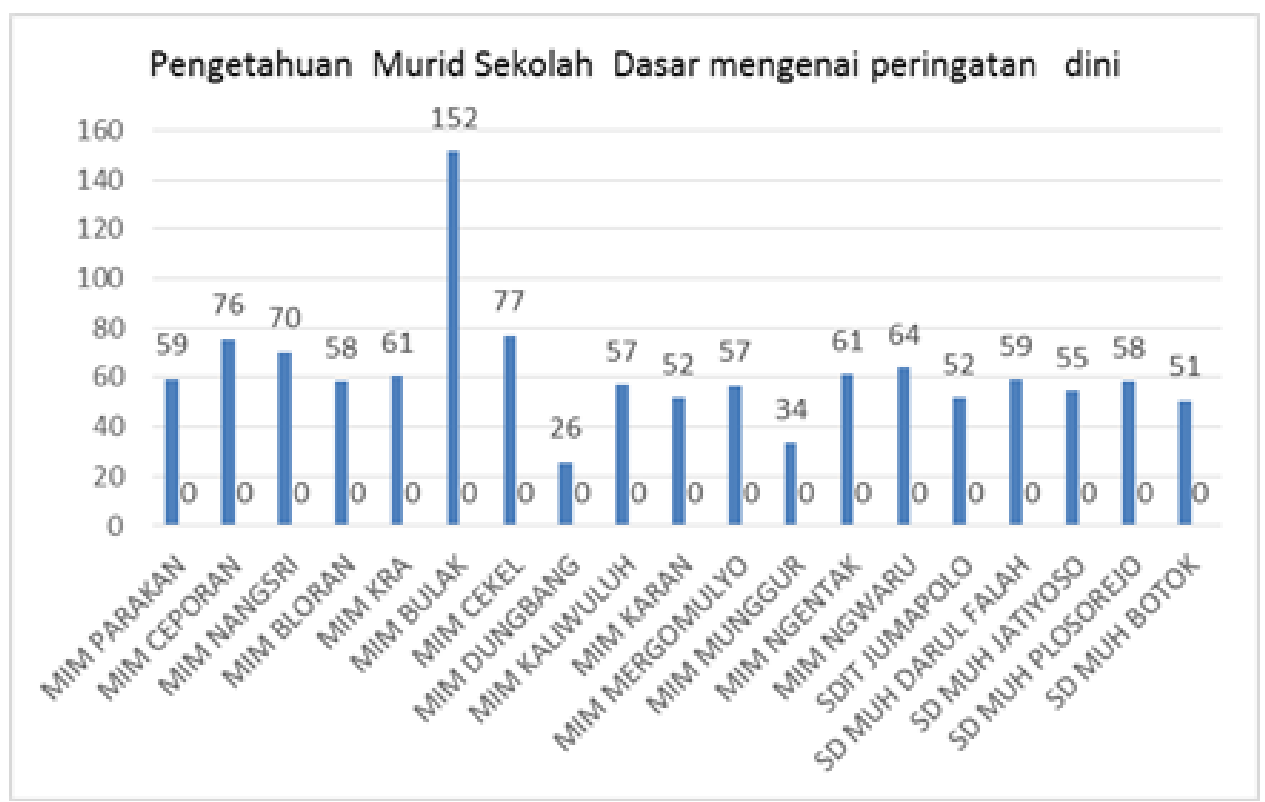

Gambar 3. Tingkat Pengetahuan Siswa SD terhadap Peringatan Dini

Tingkat Pengetahuan Siswa SMP di sekolah mengenai peringatan dini

Pada Gambar 4 di ditunjukkan bahwa tingkat pengetahuan tentang peringatan dini terhadap bencana tanah longsor pada siswa SMP Muhammadiyah yang berada di Kabupaten Karanganyar, yang meliputi MTS Muhammadiyah 2 Karanganyar (63\%), MTS Muhammadiyah 4 Karanganyar (64\%), MTS Muhammadiyah 6 Karanganyar (67\%), MTS Muhammadiyah Jumantono
(62\%), SMP 3 Muhammadiyah Karanganyar (66\%), SMP Darul Arqom (63\%), SMP Muhammadiyah 6 Jenawi Karanganyar (61\%), SMP Muhammadiyah Kebakramat (60\%), SMP Muhammadiyah 4 Mojogedang (75\%), SMP Muhammadiyah 10 Karanganyar (74\%), dan SMP Muhammadiyah 9 Jaten (68\%) . Dalam hasil grafik memperoleh tingkat nilai pengetahuan yang sedang yaitu rata - rata diatas $60 \%$ sampai $7,5 \%$ saja. 


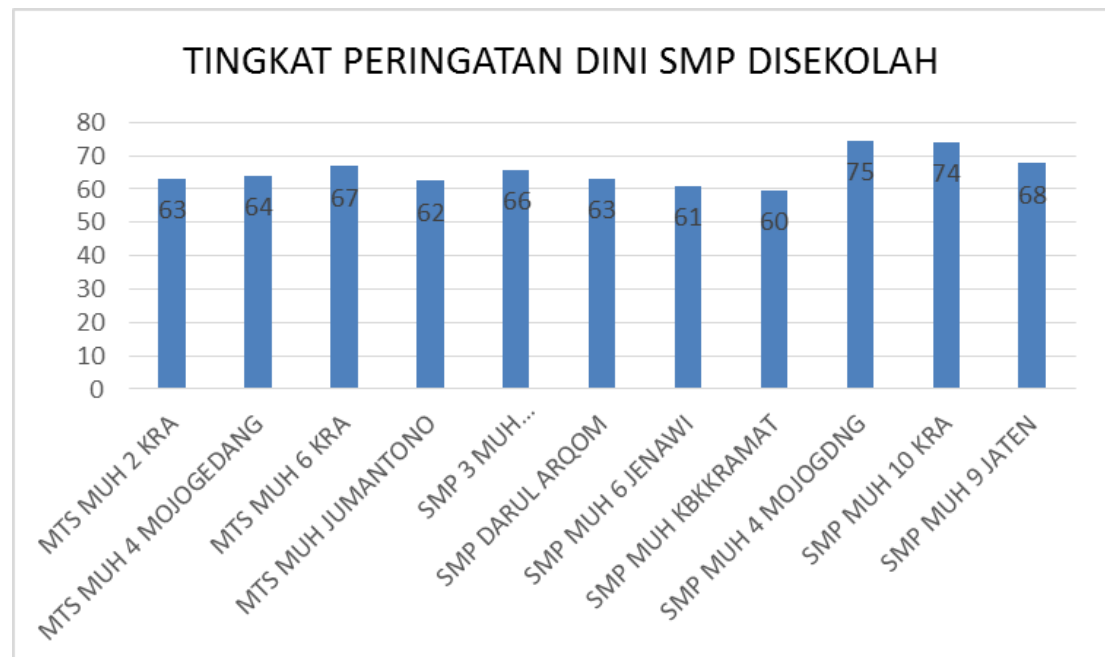

Gambar 4. Tingkat Pengetahuan Siswa SMP di sekolah mengenai peringatan dini

\section{Tingkat Pengetahuan Murid Sekolah Menengah Atas (SMA) di sekolah mengenai peringatan dini}

Pada Gambar 5 menunjukkan tingkat pengetahuan tentang peringatan dini terhadap bencana tanah longsor pada siswa SMA Muhammadiyah yang berada di Karanganyar. Hasil analisis pada grafik, diperoleh nilai tingkat pengetahuan yang berbeda - beda dari ketiga sekolah, yaitu SMA Muhammadiyah 5 Karanganyar mendapatkan nilai sedang $65 \%$, kemudian SMA Muhammadiyah 1 Karanganyar mendapatkan nilai yang paling rendah yaitu $52 \%$, sedangkan SMK Muhammadiyah 5 Karanganyar mendapatkan nilai sedang $67 \%$.

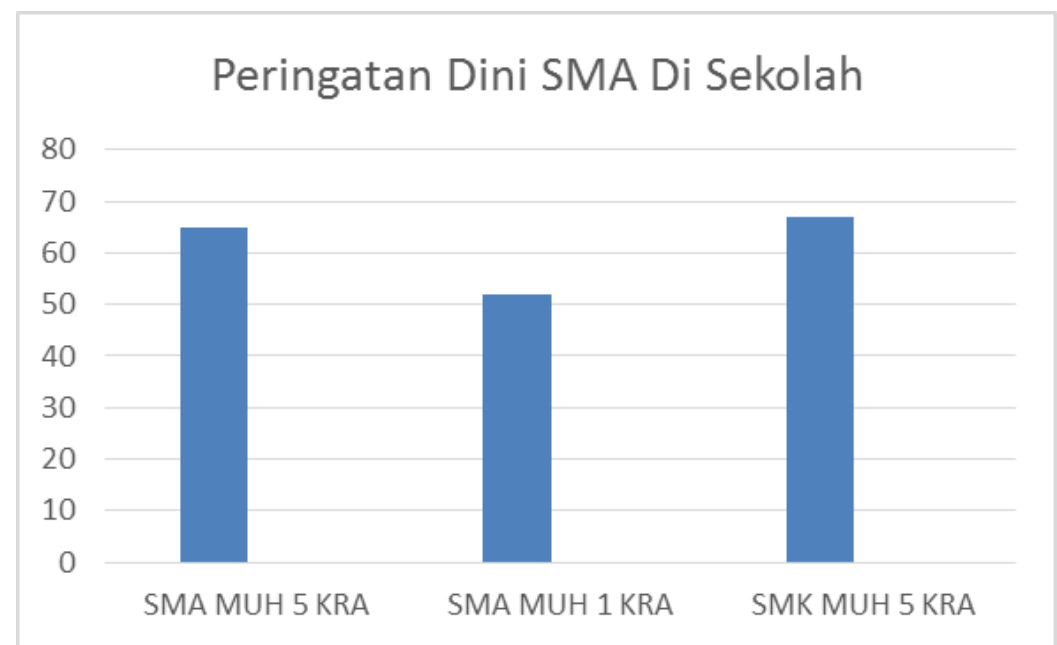

Gambar 5. Tingkat Pengetahuan Siswa SMA di sekolah mengenai peringatan dini

Hasil analisis tingkat pengetahuan peringatan dini dalam tiap sekolah (Tabel 2) menunjukkan bahwa dari 33 sekolah yang memiliki tingkat pengetahuan peringatan dini tanah longsor, terdapat 27 sekolah tergolong kategori rendah dan 6 diantaranya memiliki tingkat pengetahuan peringatan dini tanah longsor dengan kategori sedang. Banyaknya kategori rendah dari ke 33 sekolah menunjukkan bahwa masih rendahnya pengetahuan bencana dan masih kurangnya upaya dalam mempersiapkan bencana yang ada. Selain itu kondisi geografis juga sangat berpengaruh, sekolah yang menjadi sampel kebanyakan berada di lingkungan kota dan berada di tempat yang bertopografi datar membuat individu kurang mempersiapkan potensi bencana apalagi bencana tanah longsor yang dianggap tidak mungkin terjadi pada daerah tersebut. 
Tabel 1. Data Tingkat Pengetahuan Peringatan Dini Dalam Bentuk (\%)

\begin{tabular}{|c|c|c|c|c|c|c|}
\hline No & Nama Sekolah & Kepala Sekolah & Guru & Siswa & Tingkat & Kategori \\
\hline 1 & MIM KALIWULUH & 8 & 67 & 26 & 33 & Rendah \\
\hline 2 & MIM NGENTAK & 0 & 41 & 61 & 34 & Rendah \\
\hline 3 & MIM NGWARU & 0 & 40 & 64 & 35 & Rendah \\
\hline 4 & MIM MUNGGUR & 25 & 49 & 34 & 36 & Rendah \\
\hline 5 & SMA MUH 5 KARANGANYAR & 3 & 43 & 65 & 37 & Rendah \\
\hline 6 & SD MUH PLOSOREJO & 5 & 48 & 58 & 37 & Rendah \\
\hline 7 & MIM BLORAN & 10 & 52 & 58 & 40 & Rendah \\
\hline 8 & SMP MUH 4 MOJOGEDANG & 3 & 47 & 75 & 41 & Rendah \\
\hline 9 & MIM DUNGBANG & 5 & 63 & 57 & 42 & Rendah \\
\hline 10 & MIM PARAKAN & 15 & 51 & 59 & 42 & Rendah \\
\hline 11 & MTS MUH JUMANTONO & 3 & 62 & 62 & 42 & Rendah \\
\hline 12 & MTS MUH 4 MOJOGEDANG & 3 & 63 & 64 & 43 & Rendah \\
\hline 13 & MIM MERGOMULYA & 23 & 56 & 52 & 43 & Rendah \\
\hline 14 & MTS MUH 2 KARANGANYAR & 8 & 61 & 63 & 44 & Rendah \\
\hline 15 & SMP MUH 9 JATEN KARANGANYAR & 5 & 62 & 68 & 45 & Rendah \\
\hline 16 & SMP MUH 6JENAWI & 3 & 73 & 61 & 45 & Rendah \\
\hline 17 & SD MUH JATIYOSO & 20 & 62 & 55 & 46 & Rendah \\
\hline 18 & SMP MUH 10 KARANGANYAR & 8 & 62 & 74 & 48 & Rendah \\
\hline 19 & SMP DARUL ARQAM & 18 & 65 & 63 & 49 & Rendah \\
\hline 20 & SMP 3 MUH KARANGPANDAN & 3 & 79 & 66 & 49 & Rendah \\
\hline 21 & SD MUH PROGRAM UNGGULAN BOTOK & 13 & 85 & 51 & 49 & Rendah \\
\hline 22 & MTS MUH 6 KARANGANYAR & 33 & 56 & 67 & 52 & Rendah \\
\hline 23 & SD MUH DARUL FALAH & 33 & 66 & 59 & 53 & Rendah \\
\hline 24 & MIM NANGSRI & 25 & 65 & 70 & 53 & Rendah \\
\hline 25 & SD IT JUMAPOLO & 48 & 62 & 52 & 54 & Rendah \\
\hline 26 & MIM CEPORAN & 18 & 77 & 76 & 57 & Rendah \\
\hline 27 & SMK MUH 5 KARANGANYAR & 30 & 75 & 67 & 57 & Rendah \\
\hline 28 & MIM KARAN & 60 & 65 & 57 & 61 & Sedang \\
\hline 29 & SMP MUH 8 KEBAKRAMAT & 60 & 66 & 60 & 62 & Sedang \\
\hline 30 & SMA MUH 1 KARANGANYAR & 70 & 72 & 52 & 65 & Sedang \\
\hline 31 & MIM UNGGULAN KARANGANYAR & 63 & 72 & 61 & 65 & Sedang \\
\hline 32 & MIM BULAK & 3 & 45 & 152 & 66 & Sedang \\
\hline 33 & MIM CEKEL & 85 & 68 & 77 & 77 & Sedang \\
\hline
\end{tabular}

\section{ANALISIS PERBANDINGAN PERINGATAN DINI SEKOLAH}

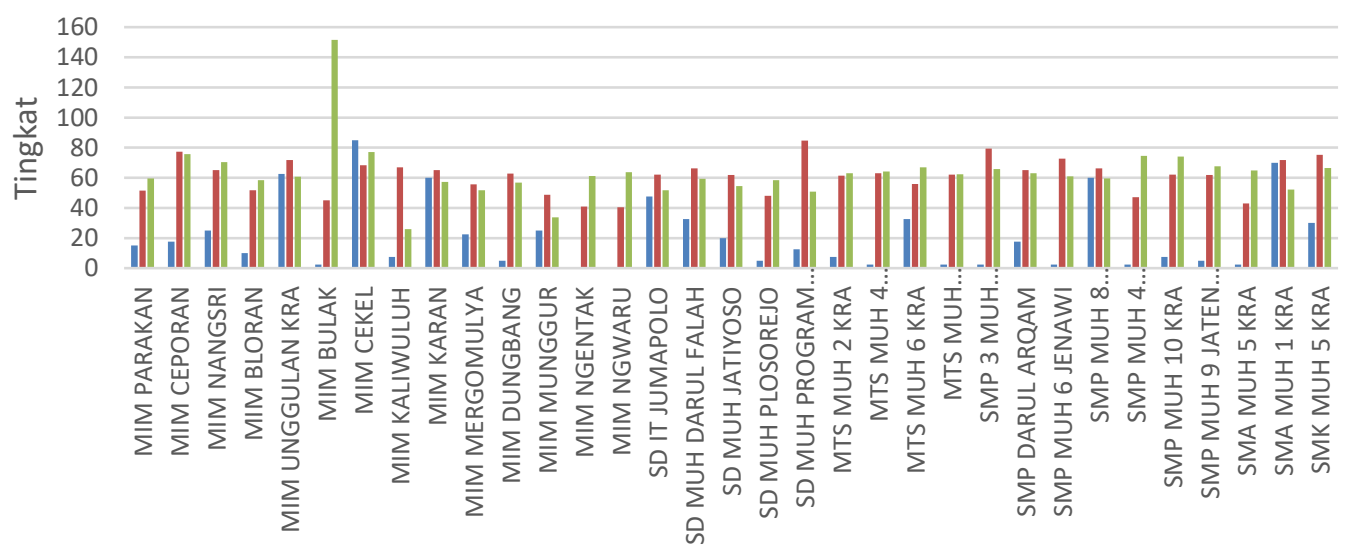

Nama Sekolah

- KEPALA SEKOLAH a GURU MURID

Gambar 6. Grafik Tingkat Perbandingan Peringatan Dini 
Berdasarkan Gambar 6, dapat dilihat bahwa tingkat perbandingan antara Kepala Sekolah, Guru, Siswa dari 33 sekolah di Kabupaten Karanganyar. Hasil tersebut menunjukkan bahwa tingkat pengetahuan antar komponen sekolah rata-rata hampir sama yaitu termasuk dalam katagori rendah.

Tingkat pengetahuan peringatan dini bencana tanah longsor yang dimiliki siswa cenderung tinggi pada tingkat sekolah menengah dan tingkat sekolah atas akan tetapi pada tingkat sekolah dasar cenderung sedang ke rendah. Hal tersebut dikarenakan kematangan usia peserta didik yang cenderung belum matang dan kurang siap terhadap pengetahuan mengenai bencana. Adanya faktor lain seperti tidak adanya materi kebencanaan dalam kurikulum membuat peserta didik asing dalam pengetahuan akan bencana. Tingginya pengetahuan bencana terutama peringatan dini tanah longsor di tingkat sekolah menengah dan tingkat sekolah atas disebabkan adanya materi kebencanaan pada materi pelajaran geografi dan adanya pengenalan materi kebencanaan seperti adanya simulasi dan sosialisasi mengenai peringatan dini tanah longsor pada ekstrakurikuler pramuka.

Adanya tingkat pengetahuan peringatan dini yang beragam di kalangan guru menunjukkan bahwa wawasan dan pengetahuan kebencanaan guru beragam pula apalagi tingkat peringatan dininya. Dari data diatas diketahui bahwa sekolah yang berada di kota memiliki guru dengan tingkat wawasan pengetahuan peringatan dini dengan kategori tinggi dan sekolah yang berada jauh di kota memiliki tingkat wawasan pengetahuan yang rendah. Hal tersebut dikarenakan bahwa suatu daerah baik kota dan desa memiliki potensi dari aspek fisik dan non fisiknya. Wilayah kota memiliki aspek fisik berupa mudahnya aksesibilitas sehingga interaksi berjalan baik antar komponen dan komunikasi lebih lancar.

Untuk tingkat wawasan pengetahuan peringatan dini dari kalangan kepala sekolah rata-rata memiliki kategori rendah. Rendahnya wawasan pengetahuan peringatan dini dapat terjadi dikarenakan kurangnya wawasan dan pengetahuan dan kurangnya sosialisasi mengenai peringatan dini.

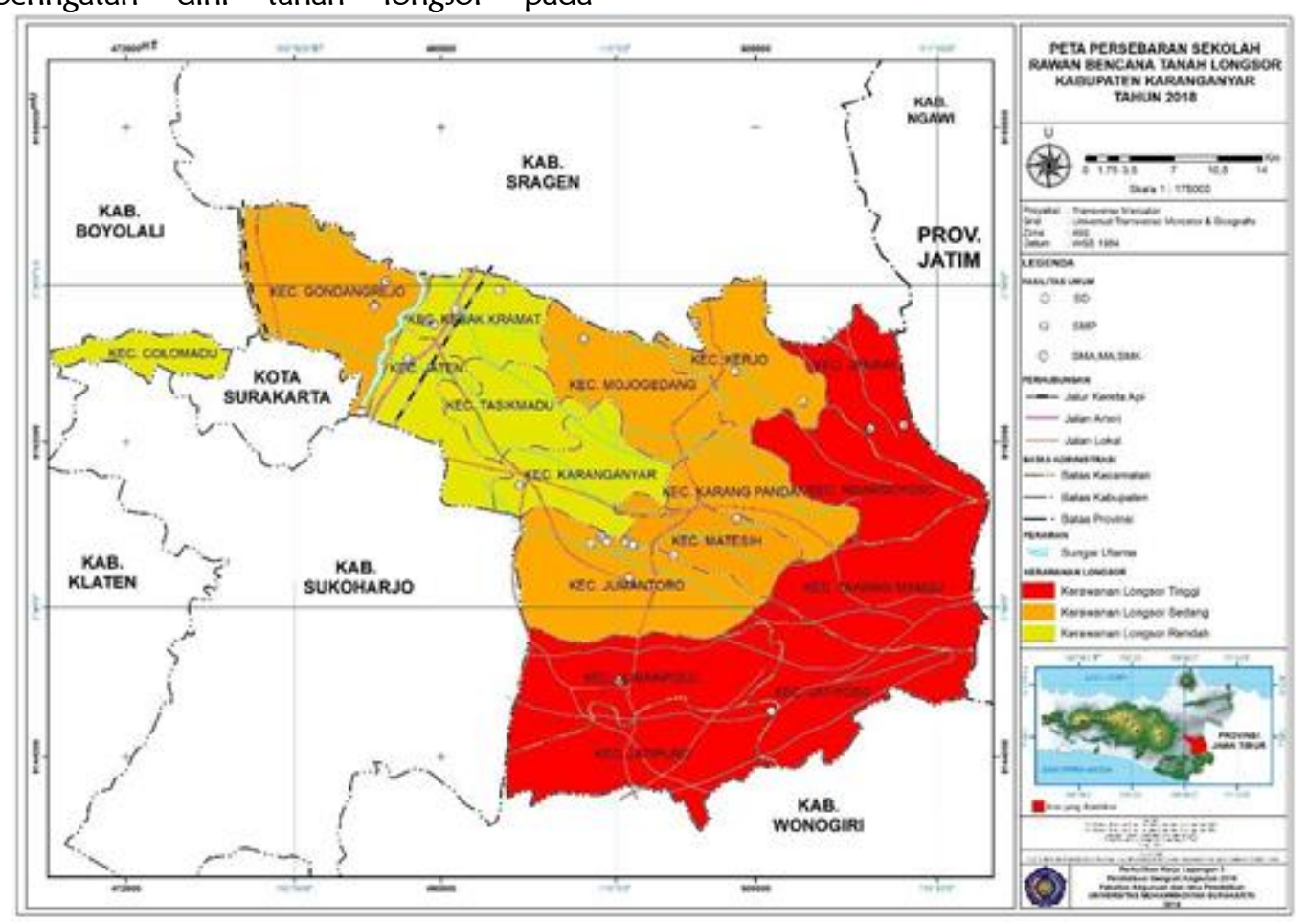

Gambar 7. Peta Kerawanan Bencana Tanah Longsor dan Persebaran Sekolah.

Berdasarkan Peta Kawasan Rawan 
Bencana Alam Kabupaten Karanganyar, sekolah yang memiliki dampak rawan longsor menengah dan rawan longsor tinggi yaitu berada di Kecamatan Jatiyoso, Kecamatan Jumapolo dan Kecamatan Jenawi. Dari data diatas diperoleh informasi bahwa 3 sekolah yang terletak di 3 Kecamatan tersebut yaitu SD IT Jumapolo, SD Muhammadiyah Jatiyoso dan SMP Muhammadiyah 6 Jenawi. Tingkat Pengetahuan mengenai peringatan dini bencana tanah longsor yang berada di Kabupaten Karanganyar menurut ketiga sekolah yaitu sebagai berikut, SD IT Jumapolo memiliki tingkat pengetahuan mengenai peringatan dini tanah longsor dilihat dari pengetahuan kepala sekolah yaitu $48 \%$ termasuk dalam kategori rendah, sedangkan dari tingkat pengetahuan guru yaitu $62 \%$ lalu dari tingkat pengetahuan murid yaitu $52 \%$ merupakan termasuk kategori rendah. Sedangkan SD Muhammadiyah Jatiyoso tingkat pengetahuan mengenai peringatan dini bencana tanah longsor dari pengetahuan kepala sekolah yaitu $20 \%$, tingkat pengetahuan Guru 62\% sedangkan dari tingkat pengetahuan murid yaitu $55 \%$ yang merupakan termasuk dalam kategori rendah. Lalu, SMP Muhammadiyah 6 Jenawi tingkat pengetahuan mengenai peringatan dini bencana tanah longsor dilihat dari pengetahuan kepala sekolah yaitu $3 \%$, tingkat pengetahuan guru $73 \%$ sedangkan tingkat pengetahuan murid yaitu $61 \%$.

Ketiga kecamatan yaitu Kecamatan Jatiyoso, Kecamatan Jumapolo dan Kecamatan Jenawi menurut Peta Kawasan Rawan Bencana Alam Kabupaten Karanganyar merupakan daerah rawan longsor karena ketiga kecamatan tersebut letaknya berada di dataran tinggi. Ketiga sekolah yang berada di ketiga kecamatan tersebut yaitu SD IT Jumapolo, SD Muhammadiyah Jatiyoso, dan SMP Muhammadiyah 6 Jenawi menunjukkan bahwa masih rendahnya pengetahuan bencana dan masih kurangnya upaya dalam mempersiapkan bencana yang ada.

\section{KESIMPULAN}

Berdasarkan pengolahan data hasil dari penelitian mengenai tingkat pengetahuan dini di sekolah se Kabupaten
Karanganyar diketahui bahwa dari 33 sekolah, 27 di antaranya memiliki tingkat pengetahuan peringatan dini yang rendah, dan 6 di antaranya memiliki tingkat pengetahuan peringatan dini dengan kategori sedang. Beberapa faktor mempengaruhi tingkat pengetahuan yang rendah dikarenakan dari aspek tingkat pendidikan siswanya. Hal tersebut dikarenakan kematangan usia siswa yang cenderung belum matang dan kurang siap terhadap pengetahuan mengenai bencana. Adanya faktor lain seperti tidak adanya materi kebencanaan dalam kurikulum membuat siswa asing dalam pengetahuan akan bencana. Tingginya pengetahuan bencana terutama peringatan dini tanah longsor di tingkat sekolah menengah dan tingkat sekolah atas disebabkan adanya materi kebencanaan pada materi pelajaran geografi dan adanya pengenalan materi kebencanaan seperti adanya simulasi dan sosialisasi mengenai peringatan dini tanah longsor pada ekstrakurikuler pramuka. Selain faktor siswa, faktor kondisi geografis juga sangat mempengaruhi karena sebagian sekolah yang dijadikan sampel penelitian berada di daerah yang tidak rawan longsor sehingga pengetahuan tentang peringatan dini sangat rendah.

\section{DAFTAR PUSTAKA}

Badan Pusat Statistik (BPS). (2018). Karanganyar dalam Angka 2018, 330.

BNPB. (2016). Risiko Bencana Indonesia (Disasters Risk of Indonesia). Retrieved from http://inarisk.bnpb.go.id/pdf/Buku RBI_Final_low.pdf

BPBD Kabupaten Karanganyar. (2012). Rekapitulasi Kejadian Bencana di Kabuapten Karanganyar Tahun 2011. BPBD Kabupaten Karanganyar.

Brannen, J. (1997). Memadu metode penelitian kualitatif dan kuantitatif. Yogyakarta: Pustaka Pelajar.

Mukhlis, T., Fathani, T. F., \& Sudarno, I. (2009). Perencanaan Sistem Peringatan Dini Bencana Tanah Longsor di Dusun Lucu Palongan Desa Campoan Kecamatan 
Mlandingan Kabupaten Situbondo Jawa Timur. In Civil Engineering Forum Teknik Sipil (Vol. 18, pp. 888-898).

Negara Kesatuan Republik Indonesia. Undang-Undang Republik Indonesia Nomor 24 Tahun 2007 tentang Penanggulangan Bencana (2007).

Setiawan, H. (2014). Analisis Tingkat Kapasitas Dan Strategi Coping Masyarakat Lokal Dalam Menghadapi Bencana Longsor-Studi Kasus Di Tawangmangu, Karanganyar, Jawa Tengah. Jurnal Penelitian Sosial Dan Ekonomi Kehutanan, 11(1), 70-81.

Setiawan, N. (2007). Penentuan Ukuran Sampel Menggunakan Rumus Slovin dan Tabel Krejcie Morgan, (November), 1-14.

Sudaryono. (2018). Metodologi Penelitian. Depok: PT. Rajagrafindo Persada.

Surakhmad, W. (1990). Pengantar penelitian ilmiah: dasar, metode dan teknik. Tarsito.

Yunus, H. S. (2010). Metodologi penelitian wilayah kontemporer. Yogyakarta: Pustaka Pelajar. 